\title{
THE IMPACT OF POPULATION DECLINE ON COUNTY GOVERNMENT FINANCE: THE WEST VIRGINIA CASE: COMMENT
}

\author{
Louis J. James
}

The University of Alabama

Professor Mikesell's primary conclusion that "net population losers" face a fiscal deficit will have serious implications for public policy at the local, state and national levels. There is, however, ample evidence that the "population gainer" jurisdictions are also faced with a fiscaldeficit. It seems reasonable to suspect that the "gainers" will successfully elicit more financial assistance from superior governments in meeting their deficit than the "losers" will obtain from these sources. As Professor Mikesell points out outside help may not be readily available as a solution.

Mikesell's conclusion that local county governments will be unable to finance their deficits by user charges because they "violate commonly held concepts of equity" must be qualified. To the extent that individual benefits rather than collective benefits accrue, efficiency requires user charges. Unless we are dealing with strong merit wants such as education or pure public goods, user charges are both efficient and equitable.

Explaining negative relationships between population and public welfare expenditure and between school administrative expenditure and public school enrollment as suggesting "possible economies of large size" may be misleading. The use of time series data and the apparent similarity between economies of scale and economies of size leaves doubts as to the explanatory value of these concepts. Quantity and quality measurements in this area are significant enough factors that "economies" of either kind may be less of an adequate explanation than the measurement problems.

In view of the experience of the 1950 's, when population shifts brought considerable pressure on the "receiving" local governments for school construction, etc., I was surprised to note the omission of any migration impact upon West Virginia in terms of capital construction (at least by the gainers). Professor Mikesell after the meetings pointed out that there had been a general absence of this type of activity in West Virginia and that was why it had been omitted. 